\title{
Performance evaluation of heat transfer and friction factor characteristics in a tube using square notched twisted tape inserts
}

\author{
Sushama Garad*, R.D.Shelke and H.N.Deshpande \\ Department of mechanical engineering, PESs Modern college of engineering, Savitribai Phule pune university, India
}

Accepted 15 June 2016, Available online 20 June 2016, Special Issue-5 (June 2016)

\begin{abstract}
The present work represents numerical analysis of square notched twisted tape insert in a tube by varying pitch with air as a working fluid. The results for simple twisted tape insert, square notched with single and double slot twisted tape insert at different twist ratio (4, 5, and 6) determined. Reynolds number varied from 35000-45000. Both pressure drop, heat transfer coefficient, Nusselt number are calculated and compared with plane tube. It is found that heat transfer enhancement of square notched twisted tape single slot and double slot is about and $32.31 \%, 39.2 \%$ as compared with plane tube.
\end{abstract}

Keywords: Heat transfer enhancement, Air, square notched twisted tape with single and double slot, CFD simulation.

\section{Nomenclature}

A Area of heat transfer, $\left[\pi d_{o} L\right]\left(\mathrm{m}^{2}\right)$

Di Inside tube diameter, $(\mathrm{m})$

Do outside tube diameter, $(\mathrm{m})$

De Depth of square cut, $(\mathrm{mm})$

W Width of square cut, $(\mathrm{mm})$

$\mathrm{Y} \quad$ Twist ratio $(\mathrm{Y} / \mathrm{W})$

L Length, (mm)

W Width of insert, $(\mathrm{mm})$

$\delta \quad$ Thickness of insert, $(\mathrm{mm})$

$\dot{\mathrm{m}} \quad$ Mass flow rate of air, $(\mathrm{kg} / \mathrm{sec})$

$\mu \quad$ dynamic viscosity of Air, (kg/s)

$\mathrm{K} \quad$ Thermal conductivity of air, $(\mathrm{W} / \mathrm{mk})$

$\mathrm{K}_{\mathrm{W}} \quad$ Thermal conductivity of copper pipe,( (W/mk)

$h_{s} \quad$ heat transfer coefficient of smooth pipe, ,(W/mk)

$h_{e} \quad$ heat transfer coefficient of the pipe using twisted tape insert, $(\mathrm{W} / \mathrm{mk})$

Q Rate of heat transfer, (W)

Q Heat flux, $\left(\mathrm{W} / \mathrm{m}^{2}\right)$

Re Reynolds number

$\mathrm{C}_{\mathrm{p}} \quad$ Specific heat of fluid, $\left(\mathrm{KJ} / \mathrm{kg}^{*} \mathrm{~K}\right)$

$\Delta \mathrm{P} \quad$ Pressure drop, $(\mathrm{KPa})$

$\Delta \mathrm{T} \quad$ Temperature difference between inlet and outlet

$T_{w i} \quad$ average inner surface temperature, $(\mathrm{K})$

$\mathrm{T}_{\text {wo }} \quad$ average is outer surface temperature, (K)

$\mathrm{T}_{\mathrm{wo}, \mathrm{i}} \quad$ local outer surface temperature,(K)

$T_{b} \quad$ bulk temperature, (K)

h Heat transfer coefficient, $\mathrm{W} / \mathrm{m}^{2} \mathrm{~K}$

$\mathrm{Nu} \quad$ Nusselt number

f Friction factor

$\rho \quad$ density of air $\left(\mathrm{kg} / \mathrm{m}^{3}\right)$

U Velocity $(\mathrm{m} / \mathrm{s})$

\begin{tabular}{ll}
\multicolumn{2}{l}{ Subscripts } \\
i & Inlet \\
o & Outlet \\
b & bulk
\end{tabular}

\section{Introduction}

Heat transfer enhancement techniques are widely used in areas like heat recovery process, air conditioning, refrigeration systems (Satyajit et al 20150, chemical reactors, process industries, heating, cooling in evaporators, thermal power plants, radiators for space vehicles, automobiles (Gawandare et al 2014).There are three main types of heat transfer enhancement techniques. They are as follows:

\section{(a) Passive technique}

The technique does not need any external power input is known as Passive technique.

These techniques generally use surface to the flow channel by incorporating inserts. They provide higher heat transfer coefficient by disturbing the flow behavior expect for extended surfaces. Heat transfer enhancement by this technique can be achieved by using treated surface, rough surface, extended surface, swirl flow devices.

\section{(b) Active technique}

The technique need any external power input is known as active technique.

Examples: mechanical aids, surface vibration, and electrostatic fields (Kanojiya et al, 2014). 


\section{(c) Compound technique}

The combination of passive and active technique may be employed simultaneously to enhance heat transfer of any device, which is greater than that of produce by any of that technique separately, then that technique is known as compound technique.

The performance evaluation of heat transfer and friction factor in a tube with different twisted tape inserts are analysed by using computational fluid dynamics (CFD), (Eisma et al 2014). The correlations for Nusselt number, heat transfer coefficient, friction factor were proposed.

In the present work presents the computational fluid dynamics (CFD) simulation i.e. flow analysis determination of heat transfer coefficient, Nusselt number, friction factor, performance evaluation criteria in a tube with square notched twisted tape with single slot, double slot for twist ratio 4,5,6, Reynolds number between 35,000 and 45,000. Then this result obtained for tube fitted with square notched twisted tape with single slot, double slot, twisted tape, plane tube compared with experimental results and literature.

\section{Literature survey details}

(Satyajit et al 2015) investigated the characteristics of heat transfer and pressure drop at a place of horizontal and double pipe with square jagged twisted tape inserts with working fluid is as water. As a result of insertion of square jagged twisted tape in concentric double tube heat exchanger gives better effectiveness on a flow friction characteristics and heat transfer rate those are experimentally investigated and shows that combination of twisted tape inserts with square jagged performs significantly better than individual enhancement technique.

(Gawandare et al 2014) Reynolds number varied from 5000 to 16000 . Increase in Nusselt number in plain twisted tape inserts with the twist ratio of 5.2 was found to be $44 \%$ and similarly for twist ratio 4.2 , 3.2 it was found to be $82 \%$ and $154 \%$ respectively. The friction factor was increased for twist ratios 5.2 in square jagged twisted tape was found to be $12 \%, 27 \%$ and $51 \%$ respectively. Researcher also concluded that the heat transfer increased up to $154 \%$ for $51 \%$ increase in friction factor, for less pumping power heat transfer rate can increase 9 .

(Krishna et al 2015) determined of friction factor and heat transfer coefficient for various twisted tape inserts with varying twists and $\mathrm{CuO}$ Nano fluid. The results of varying twists in square jagged tape with different pitches and $\mathrm{CuO}$ Nano fluid have been compared with the values for the smooth tube. The $3 \mathrm{~mm}$ thick with 4.2 twist copper insert and Nano fluid shows increase in Nusselt number values by $81 \%$ however there is increase in friction factor by only $21.5 \%$ as compared to the smooth tube values.

(Shashank et al, 2013) Cu insert has a higher heat transfer enhancement of 1.58 times as compared to plane tube. Aluminum and stainless steel insert has heat transfer enhancement of 1.41 and 1.31as compared to plane tube respectively. The friction factor was found to be increasing with decreasing coil wire pitch. It was higher for aluminum insert of $5 \mathrm{~mm}$ pitch than stainless steel and copper coil wire insert of 10 and $15 \mathrm{~mm}$ pitch respectively. The above finding indicates that copper can be used as coil wire insert material for higher heat transfer enhancement than aluminum and stainless steel.

(Naga et al 2013) Experimental investigated using five kinds $(900,600 \mathrm{FW}, 600 \mathrm{BW}, 300 \mathrm{FW}$, and $300 \mathrm{BW})$ of louvered square leaf inserts were carried out to estimate the enhancement of heat transfer rate for air in the presence of insert. Nusselt number and pressure drop increased, overall enhancement ratio is calculated to determine the optimum geometry of tube insert.

(Murugesan et al 2011) Experimental investigated of heat transfer and friction in a tube fitted with plain twisted tape (PPT) and $\mathrm{U}$ - cut twisted tapes with twist ratios 2,4.4,6. Geometries of twisted tape with twist ratios width (W) and depth (de) is 8 and $8 \mathrm{~mm}$.

(Amol et al 2014) Under turbulent condition, the increase in heat transfer rate is more than that under laminar flow condition. In this paper this literature is used for comparison with different pitch like $100,120,160$ and twist ratio 4.insertion of such geometry may lead to enhance the fiction factor and pressure drop which increases the heat transfer characteristics.

(Eisma et al 2014) The Navier-stokes equation with energy equation was solved using the $\mathrm{k}-\varepsilon$ result show that turbulence model. The experimental result show that heat transfer and friction factor increased with decreasing twist ratio.

From above literature review, it is observed that the heat transfer and friction factor characteristics using various twisted tape inserts experimentally investigated. The notched twisted tape with air is used as working fluid is not reported yet. Creation of notched at different location may enhance the heat transfer rate by reduction in pressure drop. To study this possibility square notched twisted tape with single and double slot at different twist ratio, and Reynolds Number are analysed. The geometry with best possible results is finalized for further experimental analysis.

\section{Methodology}

Table 1. Details of Test Matrix

\begin{tabular}{|c|c|c|}
\hline Inserts & Fixed parameter & $\begin{array}{c}\text { Variable } \\
\text { parameter }\end{array}$ \\
\hline Plane tape & Length of test section & $\begin{array}{c}\text { Tape pitch (y) } \\
(100,125,150)\end{array}$ \\
\hline $\begin{array}{c}\text { Aluminum twisted } \\
\text { tape }\end{array}$ & $\begin{array}{c}\text { Inner and outer } \\
\text { diameter of tube }\end{array}$ & $\begin{array}{c}\text { Twist ratio } \\
(\mathrm{y} / \mathrm{w})(4,5,6)\end{array}$ \\
\hline $\begin{array}{c}\text { Aluminum square } \\
\text { notched twisted tape }\end{array}$ & Width & $\begin{array}{c}\text { Reynolds } \\
\text { number } \\
(35000-45000)\end{array}$ \\
\hline $\begin{array}{c}\text { Aluminum square } \\
\text { notched twisted } \\
\text { tape with single slot }\end{array}$ & Twisted tape & \\
\hline $\begin{array}{c}\text { Aluminum square } \\
\text { notched twisted tape } \\
\text { with double slot }\end{array}$ & & \\
\hline
\end{tabular}




\section{Fluid flow plot analysis}

The result of heat transfer enhancement in term of Nusselt number, with the use of square notched twisted tape, square notched twisted tape with single slot, square notched twisted tape with double slot in comparison with Plain tube and twisted tape insert. For computational fluid dynamics (CFD) simulation i.e. flow analysis constant flux condition is used (1044.32 $\mathrm{W} / \mathrm{m}^{2}$ ) and wall thickness is $1.5 \mathrm{~mm}$. Tube outside (do) and inside diameter (di): 38.1 and $35.1 \mathrm{~mm}$. The heater input $(Q)$ is $125 \mathrm{~W}$.

\section{Specification of inserts}

Working fluid: Air

Material: Aluminium

Width of twisted tape (W): $25 \mathrm{~mm}$

Pitch (Y): 100,125and150mm

Twist ratio (Y/W): 4, 5, and 6.

Length of insert (L): $1000 \mathrm{~mm}$

Thickness of insert $(\delta): 1.2 \mathrm{~mm}$



Fig.1. Geometry of square notched twisted tape slot

$\mathrm{w}=8 \mathrm{~mm}$

$\mathrm{de}=8 \mathrm{~mm}$

fig1. Shows the geometry of square notch twisted tape slot. The dimensions are shown in above.

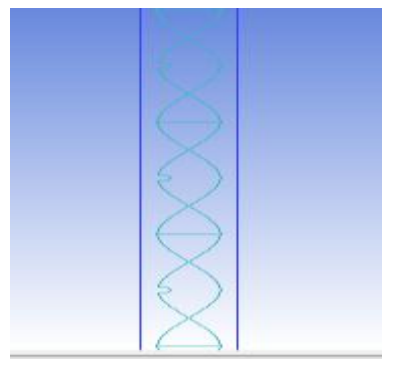

Fig.2. Geometry of square notched single slot twisted tape



Fig.3. Geometry of square notched double slot twisted tape
For single and double square notch the dimensions are, $\mathrm{w}=8 \mathrm{~mm}$ and $\mathrm{de}=8 \mathrm{~m}$

Heat transfer coefficient in case of double square notch twisted tape is higher than square notch single slot twisted tape for all pitch ratios with reduction in pressure drop because of development of secondary flow. Therefore double square notch geometry is considered for further study.

\section{Fluid flow plots}

In fig.4 a) shows fluid flow plots of pressure drop of plane tube. At the inlet pressure drop is more and at the outlet pressure drop is less. The pressure drop is $160 \mathrm{KPa}$.

Fig.4 b) shows velocity plot. At the inlet flowing the velocity more and outlet it is reduces.

\section{a) Plane tube}



Fig.4.a) Plane tube pressure drop

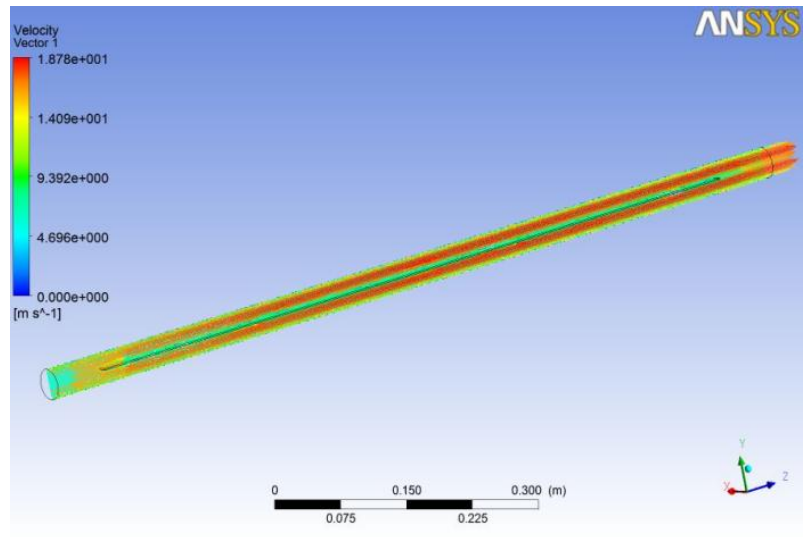

Fig. 4 b) Plane tube velocity flow 


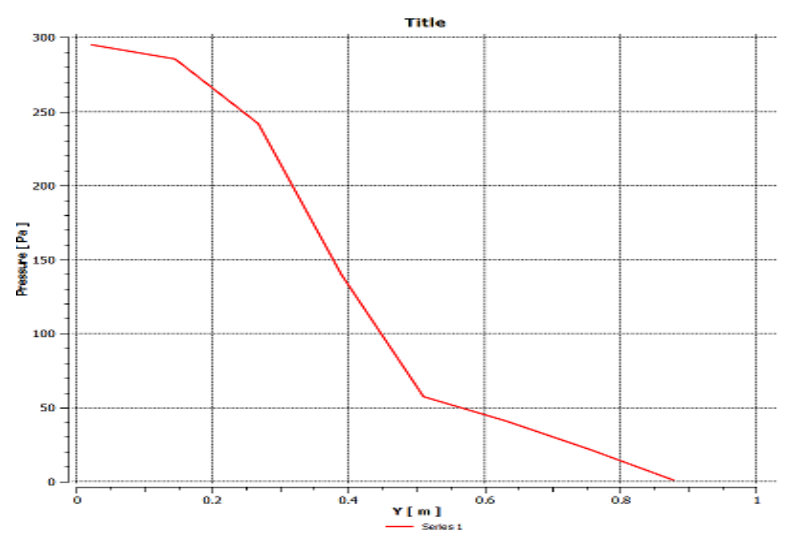

Fig.5. a) $100 \mathrm{~mm}$ pitch square notched with twisted tape insert pressure drop

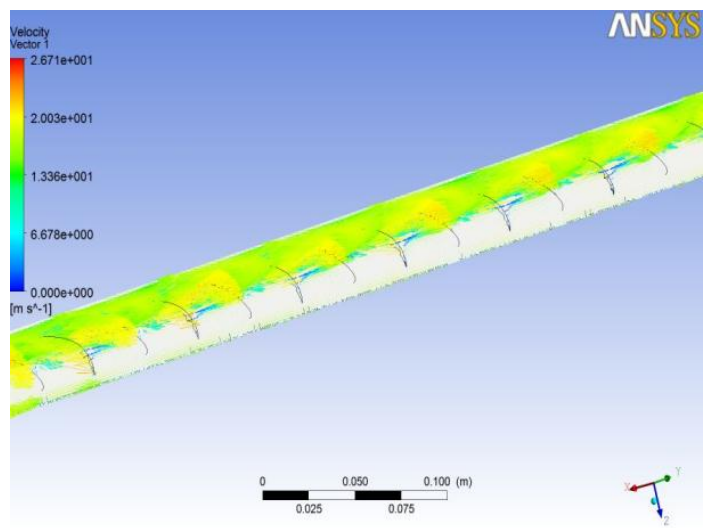

Fig.5 b) 100 pitches Square notched twisted tape velocity flow

In fig.5. a) Shows fluid flow plots of pressure drop of 100 Pitch Square notched twisted tape. At the inlet pressure drop is more and at the outlet pressure drop is less. The pressure drop is $295 \mathrm{KPa}$. Fig.5.b) shows velocity plot. At the inlet flowing the velocity more and outlet it is reduces. In fig. the velocity flow distribution is more on twisted tape. The heat transfer coefficient of square notch twisted tape is $50.12 \mathrm{~W} / \mathrm{m}^{2} \mathrm{~K}$ and Nusselt number is 70.47 .

i) $100 \mathrm{~mm}$ pitch square notched with single slot twisted tape insert

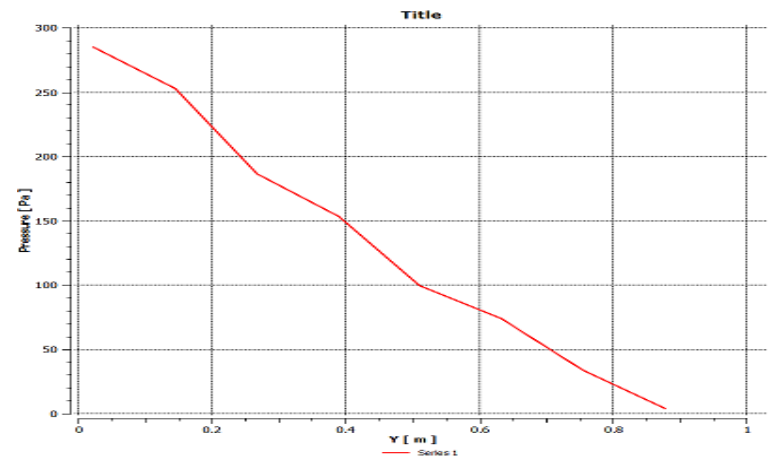

Fig.6. a) $100 \mathrm{~mm}$ pitch square notched with single slot twisted tape insert pressure drop

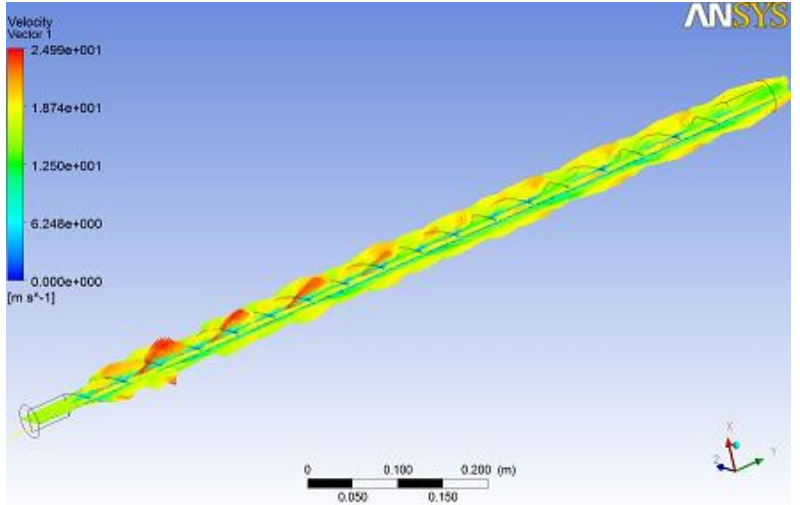

Fig. 6 b) 100mm Pitch Square notched twisted tape with single slot velocity flow

In Fig.6. a) Shows fluid flow plots of pressure drop of $100 \mathrm{~mm}$ pitch single slot square notch twisted tape. At the inlet pressure drop is more and at the outlet pressure drop is less. The pressure drop is $270 \mathrm{KPa}$. The pressure drop is reduces as compared to 100 pitch square notch twisted tape. Fig.6.b) shows velocity plot. At the inlet flowing the velocity more and outlet it is reduces. In fig. the velocity flow distribution is more on twisted tape. The heat transfer coefficient of square notch twisted tape is $53.16 \mathrm{~W} / \mathrm{m}^{2} \mathrm{~K}$ and Nusselt number is 74.23 .

ii) 100 square notched twisted tape with double slot



Fig.7.a) $100 \mathrm{~mm}$ pitch square notched with double slot twisted tape insert pressure drop

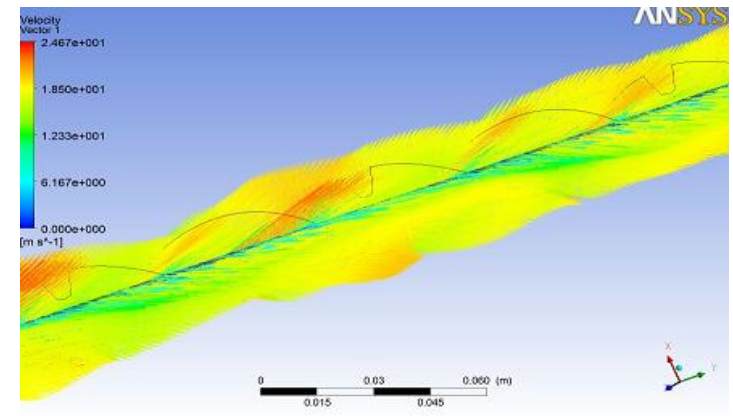

Fig.7.b) $100 \mathrm{~mm}$ pitch square notched with double Slot twisted tape insert pressure drop 
In Fig.7.a) shows fluid flow plots of pressure drop of $100 \mathrm{~mm}$ pitch double slot square notch twisted tape. At the inlet pressure drop is more and at the outlet pressure drop is less. The pressure drop is $270 \mathrm{KPa}$. The pressure drop is reduces as compared to 100 pitch square notch twisted tape. Fig.7.b) shows velocity plot. At the inlet flowing the velocity more and outlet it is reduces. In fig. the velocity flow distribution is more on twisted tape. The heat transfer coefficient of double slot square notch twisted tape is $55.8 \mathrm{~W} / \mathrm{m}^{2} \mathrm{~K}$ and Nusselt number is 78.44.

\section{c) 125 pitch twisted tape}

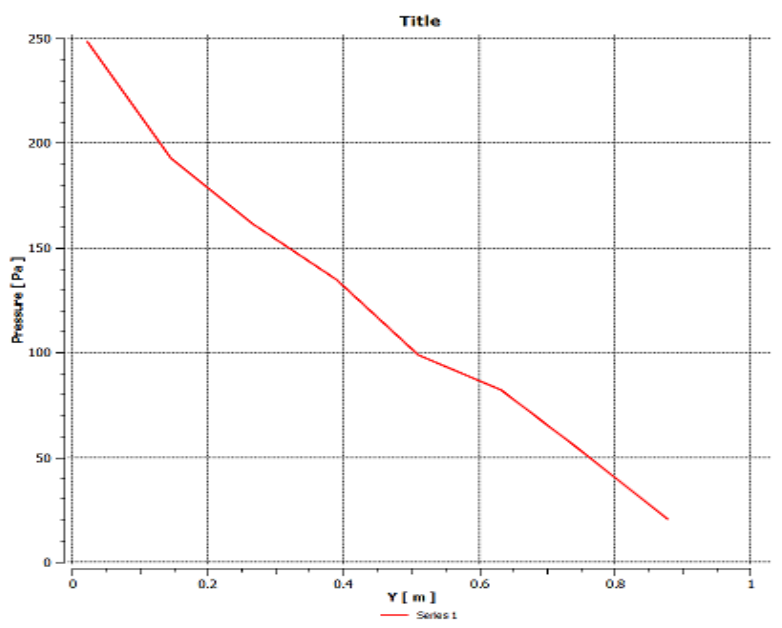

Fig.8.a) $125 \mathrm{~mm}$ pitch square notched twisted tape insert pressure drop

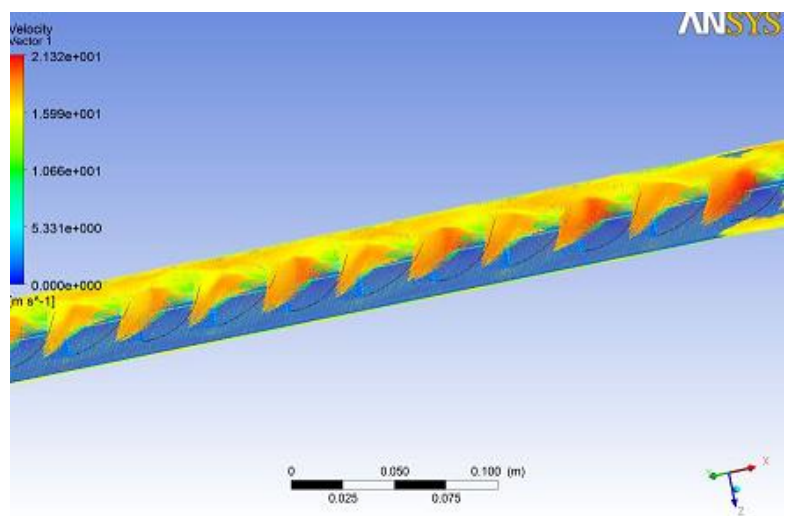

Fig.8 b) $125 \mathrm{~mm}$ pitch square notched twisted tape inserts velocity flow

In fig.8 a) shows fluid flow plots of pressure drop of $125 \mathrm{~mm}$ pitch square notched twisted tape. At the inlet pressure drop is more and at the outlet pressure drop is reduces. The pressure drop is $240 \mathrm{KPa}$. Fig.8 b) shows velocity plot. At the inlet flowing the velocity more and outlet it is reduces. In fig. the velocity flow distribution is more on twisted tape. The heat transfer coefficient of square notch twisted tape is 51.99 $\mathrm{W} / \mathrm{m}^{2} \mathrm{~K}$ and Nusselt number is 73.01.

i) 125 Square notched twisted tape with single slot

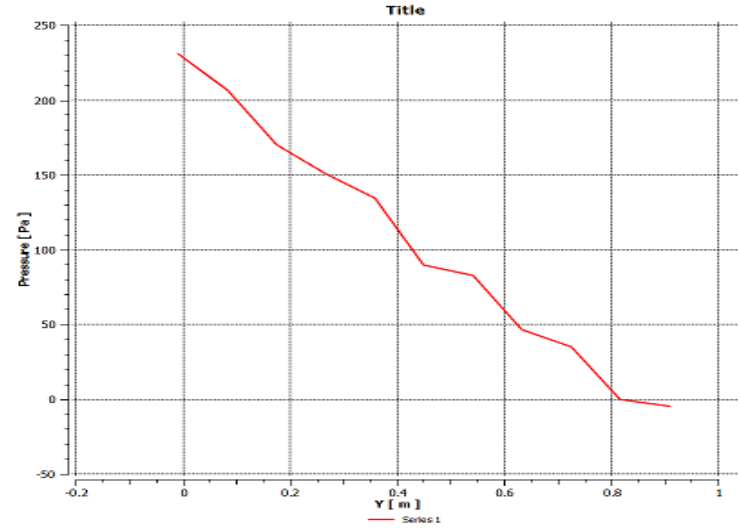

Fig.9.a) $125 \mathrm{~mm}$ pitch square notched with single slot twisted tape insert pressure drop

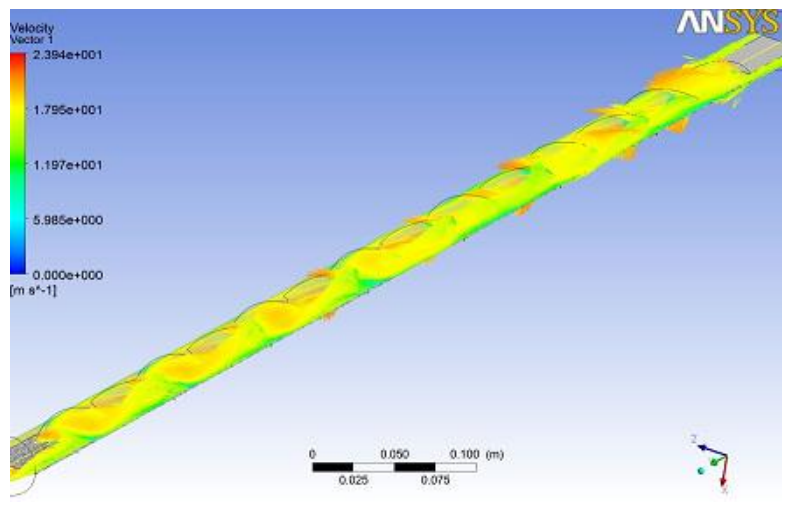

Fig.9 b) $125 \mathrm{~mm}$ pitch square notched with single twisted tape inserts velocity flow

In fig.9. a) Shows fluid flow plots of pressure drop of $125 \mathrm{~mm}$ single slot square notched twisted tape At the inlet pressure drop is more and at the outlet pressure drop is reduces. The pressure drop is $230 \mathrm{KPa}$. Fig.9.b) shows velocity plot. At the inlet flowing the velocity more and outlet it is reduces. In fig. the velocity flow distribution is more on twisted tape. The heat transfer coefficient of square notch twisted tape is 52.91 $\mathrm{W} / \mathrm{m}^{2} \mathrm{~K}$ and Nusselt number is 74.34 .

ii) 125 Square notched twisted tape with double slot

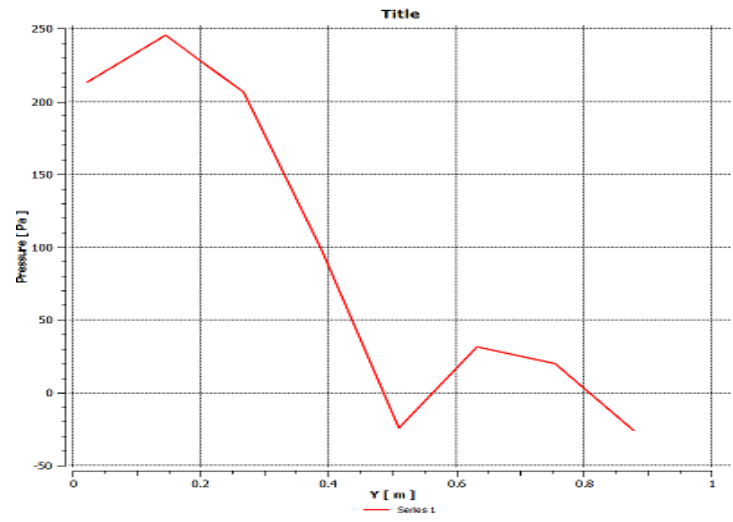

Fig.10.a) $125 \mathrm{~mm}$ pitch square notched with double slot twisted tape insert pressure drop 
From above graph it is clear that the pressure drop decreases with increasing pitch. But heat transfer coefficient increases. For double slot the heat transfer coefficient is greater compared to single slot square notch twisted tape.

\section{Mathematical correlations for CFD simulation results}

Heat transfer coefficient and pressure drop values are compared for plane tube, twisted tape, and square notched twisted tape with single and double slot. To calculated heat transfer coefficient, temperatures measured by thermocouples are used. Surface temperature and mean temperature is calculated based on thermocouples temperatures.

Velocity is calculated based on Reynolds number.

$\operatorname{Re}=\frac{\rho \mathrm{VD}_{\mathrm{o}}}{\mu}$

$P_{r}=\frac{\mu C_{p}}{K}$

$Q=h A\left(T_{s}-T_{m f}\right)$

Where,

$A=\pi D_{o} L$

Heat transfer coefficient is calculated using following,

$h=\frac{Q}{A \Delta T}$

Nusselt number is calculated using the correlation of Dittus - Boelter equation:

$N u=\frac{h D_{h}}{k}$

Friction factor is calculated using following,

$f=\frac{\Delta P}{\left[\frac{L}{d_{o}}\right]\left[\frac{\rho U^{2}}{2}\right]}$

\section{Pressure drop, heat transfer coefficient and Nusselt} number results by CFD flow simulation

Table 2. CFD flow simulation results

\begin{tabular}{|c|c|c|c|c|c|}
\hline & 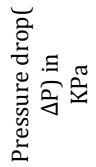 & 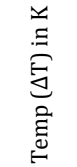 & 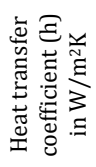 & 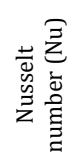 & 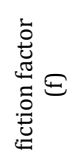 \\
\hline Plane tube & 160 & 30.80 & 33.93 & 47.70 & 0.042 \\
\hline 100 pitch & 295 & 20.85 & 50.12 & 70.47 & 0.077 \\
\hline $\begin{array}{c}100 \text { pitch } \\
\text { with single } \\
\text { slot }\end{array}$ & 280 & 19.51 & 53.16 & 74.23 & 0.073 \\
\hline $\begin{array}{l}100 \text { pitch } \\
\text { with } \\
\text { double slot }\end{array}$ & 270 & 18.73 & 55.8 & 78.44 & 0.071 \\
\hline $\begin{array}{l}125 \text { pitch } \\
\text { plain } \\
\text { twisted } \\
\text { tape }\end{array}$ & 240 & 20.1 & 51.99 & 73.01 & 0.063 \\
\hline $\begin{array}{c}125 \text { pitch } \\
\text { with single } \\
\text { slot }\end{array}$ & 230 & 19.75 & 52.91 & 74.34 & 0.063 \\
\hline $\begin{array}{l}125 \text { pitch } \\
\text { Double slot }\end{array}$ & 220 & 18.36 & 56.9 & 80.2 & 0.058 \\
\hline
\end{tabular}

\section{Experimental set up}



Fig.11. Block diagram of experimental set up

Fig.11 shows the block diagram of experimental set up. This experimental set up consist of air blower, control valve, cold and hot air, test section, thermocouples, control panel, $U$ tube manometer, heater, ammeter, voltmeter. Air blower is fitted with a tube in horizontal orientation. It is connected to a smaller diameter, insulated and electrically heated copper test section of length inner diameter. Nichrome bend heater encloses the test section to cause electric heating. The control valve in the U-shaped pipe controls the airflow rate into the test section of experiment. Power input to the test tube heater is varied using a variable transformer, which is used to vary the voltage of the AC current passing through the heater and by keeping the current less than 2A. Other thermocouples are used to measure the temperatures at various points along the test section wall. The outer surface of the test section is insulated to minimize convective heat loss to the surroundings. Pressure taping is at each end of the test section connect to another $U$ tube manometer to measure the pressure drop across the test section.

\section{Sample calculation}

The heat added by the heater was calculated by the heat added to the Air. Heat added to the air is calculated by,

$Q=\dot{\mathrm{m}} c_{p} \Delta T$

Heat transfer coefficient was calculated from,

$\left.h=\frac{q}{\left(T_{w i}-T_{b}\right.}\right)$

Bulk temperature is given by;

$\mathrm{T}_{\mathrm{b}}=\frac{\mathrm{T}_{\mathrm{i}}+\mathrm{T}_{\mathrm{o}}}{2}$

Tube outer surface temperature was calculated from the average of five local tube outer surface temperatures, 
$T_{w o}=\sum_{k i=1=0}^{n=5} \frac{T_{w 0, i}}{6}$

Tube inner surface temperatures were calculated from one dimensional radial conduction equation,

$\mathrm{T}_{\mathrm{wi}}=T_{w o}-\mathrm{Q} \frac{\ln \frac{\mathrm{d}_{0}}{\mathrm{~d}_{\mathrm{i}}}}{2 \pi \mathrm{k}_{\mathrm{wL}}}$

Reynolds number was calculated from;

$\operatorname{Re}=\frac{4 \dot{m}}{\pi d_{i} \mu}$

Nusselt number was calculated from,

$\mathrm{N}_{\mathrm{u}}=\frac{\mathrm{hd}_{\mathrm{i}}}{\mathrm{k}}$

Heat transfer enhancement efficiency was calculated from,

$\eta=\frac{h_{e}}{h_{s}}$

Thus, after calculating the heat transfer coefficient, friction factor and pressure drop characteristics of fluid flow and comparing it with each other we will be able to find out the best possible method of creating turbulence in a fluid flow thereby increasing heat transfer rate in the tube (AI Amin 2013) [10].

\section{Conclusion}

1) For 100 pitch (125 pitch also) double square notch twisted tape the heat transfer coefficient is higher than 100 pitch single square notch twisted tape.

2) For 100 pitch (125 pitch also) double square notch twisted tape the friction factor reduces as compared to 100 pitch single square notch twisted tape. Therefore this geometry is finalized.

3) Heat transfer coefficient enhanced about 32.31\%, $39.2 \%$ using square notched twisted tape insert for 100 and $125 \mathrm{~mm}$ pitch as compared to plane tube. 4] As Reynolds Number increases the Nusselt Number also increase.

\section{References}

Satyajit D.Ghorpade, K.P.Kolhe, A Review on performance evaluation of heat transfer and friction factor characteristics Of double Pipe heat exchanger fitted with square Jagged twisted tape inserts International Engineering Research Journal (IERJ), 24th April 2015, Volume 1, Issue 5 Pages 184-18

A.V.Gawandare, M.M.Dange, Heat transfer enhancement with different square jagged twisted tapes, Int. Journal of Engineering Research and Applications, March 2014,Vol. 4, Issue 3(Version 1),pages 619-624

Krishna S. Borate , A.V. Gawandare, Heat transfer Enhancement with Different Square jagged twisted tapes and $\mathrm{CuO}$ Nano fluid International Journal on Theoretical and Applied Research in Mechanical Engineering, 2015 , Volume -4, Issue-2, 2319-3182

N.C.Kanojiya, V.M.Kriplani, Heat transfer enhancement in heat exchanger with inserts: A review, Int. Journal of Engineering Research and Applications, October 2014, Vol. 3 , Issue 10

Shashank S.Choudhari, Experimental Studies on effect of coil wire Insert on heat transfer enhancement and friction factor of double pipe heat exchanger, International Journal of Computational Engineering and Research, 2013,Vol. 03, Issue 5.

S. Naga Sarada, Experimental investigations on augmentation of turbulent flow heat transfer in a horizontal tube using square leaf inserts, International Journal of Emerging Technology and Advanced Engineering, August 2013, Volume 3, Issue 8, pages 420-424.

P. Murugesan, Heat transfer and friction factor in a tube equipped with $U$ - cut twisted tape insert, Jordan journal of mechanical and industrial engineering, 6 December 2011 Volume 5, pages 559-565

Amol P, The effect of insertion of different geometries on heat transfer performance in circular pipe - A review, International journal of modern engineering research, November 2014, Volume 4, Issue 11, pages 47-53.

P. Eiamsa-ard A case study on thermal performance assessment of a heat exchanger tube equipped with regularly-spaced twisted tapes as swirl generators, Thermal engineering, 2014, Volume 3, pages 86-102.

AI Amin, Heat transfer enhancement using a rotating twisted tape inserts, science and technology conference, December 2013, pages 1-9. 